\title{
Conidia as a Substrate for Internal Transcribed Spacer-Based PCR Identification of Members of the Leptosphaeria maculans Species Complex
}

\author{
M. H. Balesdent, M. Jedryczka, L. Jain, E. Mendes-Pereira, J. Bertrandy, and T. Rouxel
}

First, fourth, fifth, and sixth authors: Pathologie Végétale, INRA, Route de Saint Cyr, 78026 Versailles Cedex, France; second author: Institute of Plant Genetics, Polish Academy of Sciences, ul. Strzeszynska 34, 60-479 Poznan, Poland; and third author: CETIOM, Centre de Biologie Appliquée, Rue de Lagny, 77178 St. Pathus, France.

Accepted for publication 3 August 1998.

\begin{abstract}
Balesdent, M. H., Jedryczka, M., Jain, L., Mendes-Pereira, E., Bertrandy, J., and Rouxel, T. 1998. Conidia as a substrate for internal transcribed spacer-based PCR identification of components of the Leptosphaeria maculans species complex. Phytopathology 88:1210-1217.

The blackleg disease of oilseed rape is caused by an ascomycete species complex termed Leptosphaeria maculans (anamorph Phoma lingam). L. maculans isolates collected worldwide were gathered in the International Blackleg of Crucifers Network (IBCN) collection. Representative IBCN isolates, along with one $P$. nigrificans isolate, were further analyzed using polymerase chain reaction (PCR) amplification of the internal transcribed spacer (ITS) region. ITS size polymorphism discriminated three groups: (i) P. nigrificans, (ii) Tox $^{+}$and 'Lepidium' isolates, and (iii) NA1,

with 19 selected endonucleases showed restriction site polymorphism between the different subgroups: digestion with RsaI could discriminate Tox ${ }^{+}$from 'Lepidium' isolates, whereas digestion with four enzymes, i.e., HaeIII, EcoRII, RsaI, and AluI, was needed to discriminate between NA1, NA2, NA3, 'Thlaspi', and 'Erysimum' isolates. No restriction site polymorphism was observed between isolates within the 'Thlaspi', Tox ${ }^{+}$, NA1, and NA2 subgroups. Direct amplification of the ITS region could be achieved using intact conidia, collected either in axenic cultures or on leaf lesions, with only a 4-min $95^{\circ} \mathrm{C}$ denaturation step prior to PCR reaction. A routine identification protocol requiring no DNA extraction and a sequential use of a few restriction enzymes following PCR has been used successfully for large-scale identification of French field isolates.
\end{abstract} NA2, NA3, 'Thlaspi', and 'Erysimum' isolates. Digestion of the ITS region
Ribosomal DNA (rDNA) genes are widely used for fungal molecular taxonomy, as they consist of a mosaic of regions exhibiting various evolutionary rates. As they are highly conserved, the rDNA sequences (18S and 26S) can discriminate at the levels of orders and kingdoms. At the species level, spacers of the rDNA and mainly the noncoding internal transcribed spacers (ITS), ITS1 and ITS2, are widely used for phylogeny studies, as they usually vary between species within a genus, but show little or no intraspecific variation (27). In addition, the high copy number of the rDNA genes along with the small size of the ITS1-5.8S-ITS2 region allow amplification with very small amounts of DNA with the polymerase chain reaction (PCR) (27). This provides unique opportunities for the detection of minute quantities of mycelia, as is often the case when a fungal pathogen establishes a compatible interaction with its host plant. As a consequence, both routine identification of a fungal species and in planta detection of a pathogen using ITS-based PCR are at hand.

In the case of the blackleg of crucifers fungus Leptosphaeria maculans (Desmaz.) Ces. \& De Not. (anamorph Phoma lingam Tode:Fr.), accurate identification tools are needed, as this pathogen represents a large species complex $(22,23)$. L. maculans obtained from cultivated Brassica spp. has long been considered a single species divided into aggressive and nonaggressive pathotypes (19, 23). The development of more accurate biochemical and molecular characterization methods recently demonstrated that these two

Corresponding author: T. Rouxel; E-mail address: thierry.rouxel@ versailles.inra.fr

Publication no. P-1998-0916-01R

(C) 1998 The American Phytopathological Society
Brassica pathotypes, also termed $\mathrm{Tox}^{+}$(i.e., aggressive) and $\mathrm{Tox}^{0}$ (i.e., nonaggressive), should be considered two distinct species (4, 17). As more molecular tools became available to study the complex $(8,15,20,25)$, more subgroups or subspecies were discriminated. For example, the nonaggressive or $\mathrm{Tox}^{0}$ species was further separated into three subgroups: NA1, NA2, and NA3 $(7,11)$, and the anamorph of NA2 isolates was related to $P$. wasabiae (18). In addition, isolates of $L$. maculans were obtained from cruciferous weeds and termed 'Thlaspi', 'Sisymbrium', 'Lepidium', 'Erysimum', etc., depending on their host plant (19). Of these, only the 'Thlaspi' type has ever been compared with $L$. maculans isolated from Brassica using molecular methods and was shown to be different from both $\mathrm{Tox}^{+}$and Tox ${ }^{0}$ NA2 (17). Finally, one Phoma isolate was recently isolated from Thlaspi arvense in Poland and identified as $P$. nigrificans $(10,14)$. Because of uncertain taxonomical relationships within the species complex and the lack of a commonly accepted terminology, the International Blackleg of Crucifers Network (IBCN) was organized to gather a worldwide collection of $L$. maculans and advance the knowledge of what is termed L. maculans in various parts of the world $(24,26)$. Isolates 'Leroy', 'Unity', PHW1268, and PHW1270, which were first characterized as $\operatorname{Tox}^{+}, \operatorname{Tox}^{0} \mathrm{NA} 2, \operatorname{Tox}^{0} \mathrm{NA} 3$, and $\operatorname{Tox}^{0} \mathrm{NA} 1$, respectively, (11) are included in the IBCN collection and are used as reference isolates in the current study.

ITS sequencing of a few L. maculans isolates confirmed the discrimination between $\mathrm{Tox}^{+}$, NA2, and 'Thlaspi' isolates from Canada, Australia, or both $(17,29)$. Specific primers were designed from these sequences for a PCR-based discrimination between $\mathrm{Tox}^{+}$and NA2 isolates (29). However, no ITS sequence data is available for the other components of the complex, particularly NA1 isolates, which are the prevalent $\operatorname{Tox}^{0}$ in Europe $(2,7,9)$. The 
objective of the current paper is to propose a simplified and easyto-use procedure for large-scale identification of all members of the L. maculans species complex on the basis of restriction analysis of the ITS region (ITS1-5.8S-ITS2) following PCR amplification (restriction fragment length polymorphism [RFLP]-PCR). A decision strategy for identification of all members was designed using DNA of IBCN isolates representative of the following subgroups: (i) $\mathrm{Tox}^{+}$; (ii) $\mathrm{Tox}^{0} \mathrm{NA} 1$; (iii) $\mathrm{Tox}^{0} \mathrm{NA} 2$; (iv) $\mathrm{Tox}^{0} \mathrm{NA} 3$; (v) 'Thlaspi'; (vi) 'Lepidium'; and (vii) 'Erysimum', to which was added the $P$. nigrificans isolate. In a second step, the decision strategy was assessed for reliability using DNA of 49 additional isolates. A protocol was then established allowing direct amplification of the ITS region using conidia as a substrate instead of extracted DNA. Finally, the usefulness of the RFLP-PCR protocol using conidia as a PCR template was investigated for large-scale analysis of French populations of $L$. maculans.

\section{MATERIALS AND METHODS}

Fungal strains and culture maintenance. Partial sequencing of the ITS region and choice of informative enzymes were performed on extracted DNA from one representative isolate each of Tox $^{+}$, Tox $^{0}$ NA1, Tox ${ }^{0}$ NA2, and Tox ${ }^{0}$ NA3 along with IBCN isolates identified on the basis of their host plant, i.e., 'Thlaspi', 'Lepidium', and 'Erysimum' (Table 1). One P. nigrificans isolate and five previously characterized $L$. maculans isolates from France, Poland, and the United Kingdom were also used for this part of the study (Table 1). Additional validation of the decision strategy was performed on extracted DNA of 4 additional IBCN isolates, 1 Danish isolate, 5 United Kingdom isolates, and 34 single-conidium Polish isolates obtained from stem lesions (Table 2). IBCN isolates were characterized according to mycelial soluble protein profiles and isozyme studies as already described $(4,7)$. United Kingdom, Danish, and Polish isolates have been characterized according to their ability to produce in vitro toxins of the sirodesmin family and repetitive element based-PCR profiles (9; M. Jedryczka and P. Kachlicki, unpublished data). Finally, the accuracy of the RFLP-PCR protocol using conidia was further assessed on 356 French field isolates. These latter isolates were collected by the CETIOM in six locations in France (Surgères, southwestern; Beziers, southern; Saint Florent, central; Dijon and Nancy, eastern; and Saint Pathus, northcentral). Isolates were collected in autumn 1995 and 1996, winter and summer 1996, and winter 1997 from leaves and stems of B. napus displaying symptoms or apparently healthy.

All fungal cultures were maintained on V-8 juice agar medium. Highly sporulating cultures were obtained on V-8 juice agar according to the procedure described by Ansan-Melayah et al. (1).

Fungal DNA extraction. Conidia were collected from 12-dayold sporulating cultures. Approximately $10^{8}$ conidia were inoculated onto $100 \mathrm{ml}$ of modified Fries medium in Roux bottles (Fisher Scientific S.A., Elancourt, France) (4). Four-day-old mycelium was harvested by vacuum filtration on sterile muslin, frozen at $-20^{\circ} \mathrm{C}$, and freeze-dried. DNA was extracted following a modified Dellaporta et al. (5) protocol. Freeze-dried mycelium was ground with forceps in a $1.5-\mathrm{ml}$ microfuge tube, so that approximately $100 \mu \mathrm{l}$ of powder was obtained. Two hundred microliters of lysis buffer (50 mM Tris- $\mathrm{HCl}, \mathrm{pH} 8 ; 50 \mathrm{mM}$ EDTA; $2 \%$ sodium $N$-lauroyl sarcosinate; and $150 \mathrm{mM} \mathrm{NaCl}$ ) and $200 \mu \mathrm{l}$ of phenol (saturated with $1 \times$ Tris- $\mathrm{HCl}, \mathrm{pH} 8$ ) were added, and lysis took place on ice for $1 \mathrm{~h} 30 \mathrm{~min}$ with occasional vortexing. The mixture was centrifuged for $5 \mathrm{~min}$ at $13,000 \times g$ at $4^{\circ} \mathrm{C}$. The aqueous phase was centrifuged an additional $15 \mathrm{~min}$, the supernatant transferred to a new tube, and nucleic acids were precipitated using 0.6 volume of isopropanol at $-20^{\circ} \mathrm{C}$. Recovery of DNA in Tris-EDTA buffer and digestion of RNA took place according to Ansan-Melayah et al. (1).

PCR amplification from DNA. Primers used for ITS amplification and sequencing were deduced from flanking sequences of Saccharomyces cerivisiae (13), i.e., the $18 \mathrm{~S}$ rDNA for primer PN3 (forward) (5'-CCGTTGGTGAACCAGCGGAGGGATC-3') and the 28S rDNA for primer PN10 (reverse) (5'-TCCGCTTATTGATATGCTTAAG-3') (Life Technologies, Inc., Gaithersburg, MD). Amplifications were performed in 25 - or $50-\mu$ f final volumes containing $50 \mathrm{ng}$ of template DNA, $200 \mu \mathrm{M}$ of each desoxyribonucleotide triphosphate, $2.5 \mu \mathrm{M}$ of each primer, $1.5 \mathrm{U}$ (for $25-\mu \mathrm{l}$ mixes) or $3 \mathrm{U}$ (for 50- $\mu$ l mixes) of Taq polymerase (Appligene-Oncor, Pleasanton, $\mathrm{CA})$ in $1 \times \operatorname{Taq}$ DNA incubation mix (10 mM Tris-HCl, $\mathrm{pH} 9.0 ; 50$ $\mathrm{mM} \mathrm{KCl} ; 1.5 \mathrm{mM} \mathrm{MgCl}_{2} ; 0.1 \%$ Triton X-100; and $0.2 \mathrm{mg}$ of bovine serum albumin per $\mathrm{ml}$ ) (Appligene-Oncor). The reaction was performed for 37 cycles in a GeneAmp PCR system 9600 (PerkinElmer/Applied Biosystems, Norwalk, CT). Each cycle consisted of $30 \mathrm{~s}$ at $94^{\circ} \mathrm{C}, 30 \mathrm{~s}$ at $58^{\circ} \mathrm{C}$, and $1 \mathrm{~min}$ at $72^{\circ} \mathrm{C}$.

PCR amplification using conidia as a template. $\mathrm{PCR}$ reaction mix was as above, except that DNA was omitted and replaced by water. PCR tubes containing $25 \mu \mathrm{l}$ of the reaction mix were maintained on ice. The ooze of one or two pycnidia from axenic 12-dayold sporulating cultures was collected with a sterile needle using a $\times 15$ magnification and immediately dipped in the PCR reaction mix. Using this technique, approximately $0.5 \times 10^{6}$ to $2 \times 10^{6}$ conidia were suspended in the mix. PCR conditions were as follows: a preliminary denaturation step of $4 \mathrm{~min}$ at $95^{\circ} \mathrm{C}$ to lyse the conidia, and then 37 cycles of $15 \mathrm{~s}$ at $94^{\circ} \mathrm{C}, 15 \mathrm{~s}$ at $58^{\circ} \mathrm{C}$, and $30 \mathrm{~s}$

TABLE 1. List and characteristics of isolates used to design the decision strategy following restriction fragment length polymorphism polymerase chain reaction of the internal transcribed spacer region

\begin{tabular}{|c|c|c|c|c|c|c|}
\hline Isolate number & IBCN number ${ }^{\mathrm{a}}$ & Geographic origin & Isolated from & Originator & Strain type ${ }^{b}$ & Reference \\
\hline \multicolumn{7}{|c|}{ Reference isolates } \\
\hline $92-01-2$ & 65 & Canada & Thlaspi arvense & G. Séguin-Swartz & 'Thlaspi' & \\
\hline 'Leroy' & 80 & Canada & Brassica napus & G. A. Petrie & Tox $^{+}$ & 11,17 \\
\hline Ery-2 & 83 & Canada & Erysimum sp. & G. Séguin-Swartz & 'Erysimum' & \\
\hline Lep-2 & 84 & Canada & Lepidium sp. & G. Séguin-Swartz & 'Lepidium' & \\
\hline PHW1268 & 91 & United States & B. oleracea & P. H. Williams & Tox ${ }^{0}$ NA3 & 7,11 \\
\hline PHW1270 & 93 & France & B. oleracea & P. H. Williams & Tox $^{0} \mathrm{NA} 1$ & 7,11 \\
\hline \multicolumn{7}{|l|}{ Other isolates } \\
\hline H5 & & France & B. napus & C. Gall & Tox $^{+}$ & 1,4 \\
\hline WHA & & United Kingdom & B. napus & B. Fitt & Tox $^{0} \mathrm{NA} 1$ & 9 \\
\hline $\mathrm{Ph} 3$ & & Poland & B. napus & M. Jedryczka & Tox $^{0}$ NA1 & 9 \\
\hline PL53 & & Poland & B. napus & M. Jedryczka & Tox $^{0} \mathrm{NA} 1$ & \\
\hline Raw5 & & Poland & B. napus & M. Jedryczka & Tox $^{0}$ NA1 & \\
\hline
\end{tabular}

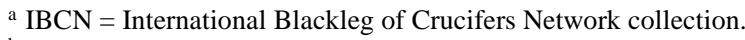

${ }^{\mathrm{b}}$ Strain type according to the originator or reference. 
(with an increase of $1 \mathrm{~s}$ per cycle) at $72^{\circ} \mathrm{C}$. The same protocol was used with conidia oozing from pycnidia differentiated on infected cotyledons. In this case, cotyledons of 15-day-old plantlets were inoculated with conidia suspensions of known $\mathrm{Tox}^{+}$isolates, as described previously (1). Following 14 to 18 days of incubation in the growth chamber, lesions showing pycnidia were cut off the cotyledons and incubated under saturating humidity for 24 to $48 \mathrm{~h}$ at room temperature, therefore, allowing pycnidia to ooze conidia.

Digestion of the ITS region. Six to eight microliters of the PCR products was digested for 2 to $5 \mathrm{~h}$ with $10 \mathrm{U}$ of one of the following enzymes: AccI, AluI, BamHI, ClaI, EcoRI, EcoRII, HaeIII, HindIII, HinfI, MspI, NlaIV, NcoI, RsaI, Sau3AI, ScrFI, SphI, StyI, TaqI, or XmaI (Eurogentec SA, Seraing, Belgium), according to the manufacturer's recommendations.

Fragment analysis. PCR products and restriction fragments were analyzed following electrophoresis in 1.4 to $1.8 \%$ agarose gels with $1 \times$ TBE (45 mM Tris-borate and $1 \mathrm{mM}$ EDTA, $\mathrm{pH} 8$ ) as a buffer and staining with $0.5 \mu \mathrm{g}$ of ethidium bromide per ml. As an alternative, 3 to $3.5 \%$ MetaPhor agarose gels (FMC BioProducts, Rockland, ME) were used to separate restriction fragments. Gels were viewed and recorded using the Gel Doc 1000 fluorescent gel documentation system (Bio-Rad, Hercules, CA). Molecular weights were calculated with the Molecular Analyst v. 1.4 software (BioRad) using the 1-kb, 100-bp, and 10-bp ladder (Life Technologies, Inc.) as references.

ITS sequencing and sequence analysis. Partial sequencing of the ITS region was performed to confirm restriction site locations. Amplified ITS PCR products from isolates Phb, IBCN65, IBCN81, IBCN83, IBCN84, IBCN91, H5, Raw5, WHA, and PL53 were purified from the agarose gel with the JETsorb kit (GenoMed, Research Triangle Park, NC). Purified fragments were quantified

TABLE 2. List and characteristics of isolates used for validation of the decision strategy using DNA as a polymerase chain reaction template

\begin{tabular}{|c|c|c|c|}
\hline Isolate number & $\begin{array}{c}\text { Geographic } \\
\text { origin }\end{array}$ & Originator & Strain type \\
\hline IBCN48 & France & P. Chandelier & Tox $^{0}$ NA1 \\
\hline IBCN63 & Canada & G. Séguin-Swartz & $\operatorname{Tox}^{0} \mathrm{NA} 2$ \\
\hline IBCN64 & Canada & G. Séguin-Swartz & 'Thlaspi' \\
\hline IBCN82 & Canada & G. Séguin-Swartz & $\mathrm{Tox}^{0} \mathrm{NA} 2$ \\
\hline Fp2 & Denmark & M. Jedryczka & $\operatorname{Tox}^{+}$ \\
\hline $\begin{array}{l}\text { Ph2, PhL6, Ph24, PhS1, PhGosc, } \\
\text { PhTrzy, PhEP, CER A, PL35, } \\
\text { PL36, PL40, PL41, PL43, PL46, } \\
\text { PL48-50, PL54, PL55, PL57, PL58, }\end{array}$ & & & \\
\hline PL60, PL61, PL63-67, PL70 & Poland & M. Jedryczka & Tox $^{0}$ NA1 \\
\hline PhL5, Raw4, PhBial, PL47, PL56 & Poland & M. Jedryczka & $\operatorname{Tox}^{+}$ \\
\hline DL3, DL32, Ak1/10, L4, E(Box)126b & United Kingdom & B. Fitt & $\operatorname{Tox}^{+}$ \\
\hline
\end{tabular}

on agarose gels using the DNA mass ladder (Life Technologies, Inc.) as a standard. Cycle sequencing took place on the GeneAmp PCR system 9600 utilizing the ABI PRISM dye terminator cycle sequencing ready reaction kit (Perkin-Elmer/Applied Biosystems) with primers PN3 or PN10 and $100 \mathrm{ng}$ of template DNA per reaction. Sequencing was performed with the ABI PRISM 310 genetic analyzer (Perkin-Elmer/Applied Biosystems), using polymer POP-6 and a 61-cm capillary column according to the manufacturer's directions. All sequence analyses were performed with the Wisconsin Package version 9.0 software (Genetics Computer Group, Madison, WI).

\section{RESULTS}

ITS size polymorphism between members of the $L$. maculans species complex. Size polymorphism of the ITS region was evident following amplification of fungal DNA using the PN3 and PN10 primers (Table 3, Figs. 1 and 2A). Four main size classes could be distinguished: (i) 520 to $530 \mathrm{bp}$ for P. nigrificans, (ii) 555 to 560 bp for Tox ${ }^{+}$isolates, (iii) 570 to 575 bp for the 'Lepidium' isolate, and (iv) 580 to 585 bp for all Tox ${ }^{0}$, 'Thlaspi', and 'Erysimum' isolates. According to the sequence of the L. maculans $18 \mathrm{~S}$ (16), the PN3 primer hybridizes to bases 1,783 to 1,807 of the $18 \mathrm{~S}$ rDNA, i.e., bases -29 to -5 before the beginning of ITS1. According to sequences encompassing ITS2 and the beginning of the $26 \mathrm{~S}$ in L. maculans (e.g., accession numbers M96383 and M96384

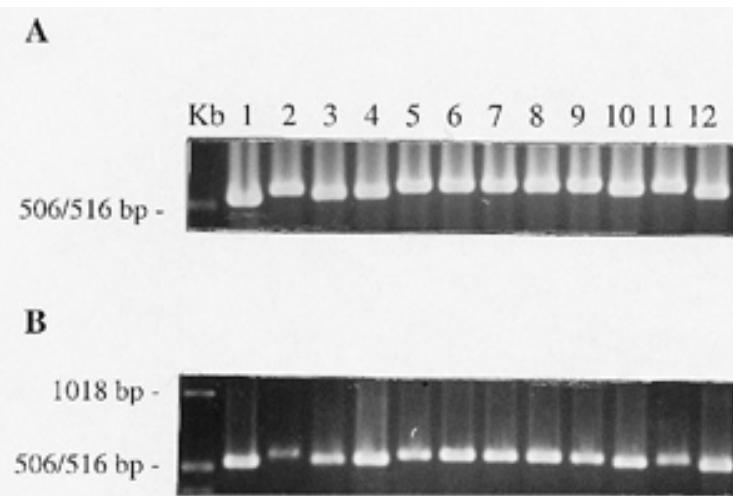

Fig. 1. Internal transcribed spacer (ITS) size polymorphism observed following amplification using A, DNA or $\mathbf{B}$, conidia as a polymerase chain reaction template. 1, Phoma nigrificans isolate $\mathrm{Phb} ; 2$, NA1 isolate $\mathrm{Ph} 2$; 3 , Tox ${ }^{+}$isolate 'Leroy' (IBCN80); 4, Tox ${ }^{+}$isolate Raw4; 5, 'Erysimum' isolate Ery-2 (IBCN83); 6, NA2 isolate 'Unity' (IBCN81); 7, NA1 isolate Ph3; 8, 'Thlaspi' isolate 92-01-2 (IBCN65); 9, NA3 isolate PHW1268 (IBCN91); 10, 'Lepidium' isolate Lep-2 (IBCN84); 11, NA1 isolate PHW1270 (IBCN93); and $12, \mathrm{Tox}^{+}$isolate $\mathrm{H} 5 . \mathrm{Kb}=1-\mathrm{kb}$ ladder.

TABLE 3. Internal transcribed spacer (ITS) size polymorphism among components of the Leptosphaeria maculans species complex

\begin{tabular}{|c|c|c|c|c|c|}
\hline Strain type & Isolate number & $\begin{array}{l}\text { Estimated size for the } \\
\text { amplified fragment (bp) }\end{array}$ & $\begin{array}{l}\text { Estimated size for the } \\
\text { ITS1-5.8S-ITS2 region }(b p)^{b}\end{array}$ & $\begin{array}{l}\text { ITS region size, based on } \\
\text { sequence data }\end{array}$ & $\begin{array}{l}\text { ITS region size, based on } \\
\text { published sequence data }\end{array}$ \\
\hline Phoma nigrificans & Phb & $520-530$ & $435-445$ & 439 & \multirow{8}{*}{470 (M96384) } \\
\hline \multirow[t]{2}{*}{$\operatorname{Tox}^{+}$} & 'Leroy' & $555-560$ & $470-475$ & 470 & \\
\hline & H5 & $555-560$ & $470-475$ & 471 & \\
\hline 'Lepidium' & Lep-2 & $570-575$ & $485-490$ & 481 & \\
\hline \multirow[t]{4}{*}{$\operatorname{Tox}^{0} \mathrm{NA} 1$} & PHW1270 & $580-585$ & $495-500$ & 497 & \\
\hline & WHA & $580-585$ & $495-500$ & 496 & \\
\hline & PL53 & $580-585$ & $495-500$ & 494 & \\
\hline & Raw5 & $580-585$ & $495-500$ & 497 & \\
\hline $\mathrm{Tox}^{0} \mathrm{NA} 2$ & 'Unity' & $580-585$ & $495-500$ & 498 & \multirow[t]{2}{*}{498 (M96383, U19274, L07735) } \\
\hline Tox $^{0}$ NA3 & PHW1268 & $580-585$ & $495-500$ & 499 & \\
\hline 'Thlaspi' & $92-01-2$ & $580-585$ & $495-500$ & 499 & 499 (M96663) \\
\hline 'Erysimum' & Ery-2 & $580-585$ & $495-500$ & 497 & \\
\hline
\end{tabular}

a Estimated size for the fragment generated by the PN3 and PN10 primers, following agarose gel electrophoresis (Fig. 1).

b Size of the ITS1-5.8S-ITS2 region as calculated from the location of the PN3 and PN10 primers on the ribosomal DNA genes.

c Molecular weights according to sequence analysis performed in this study.

${ }^{\mathrm{d}}$ Molecular weight and GenBank accession number (in parentheses) deduced from published sequences. 
A
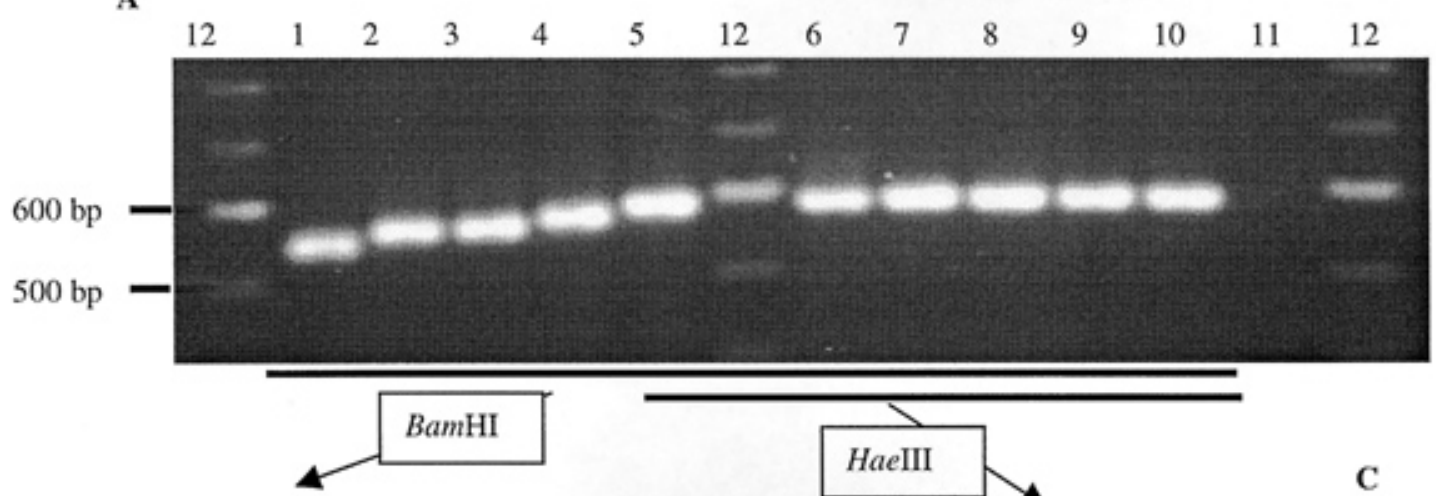

B

$\begin{array}{llllllllllllll}12 & 1 & 2 & 3 & 4 & 12 & 5 & 6 & 7 & 8 & 9 & 10 & 12\end{array}$

$\begin{array}{llllllllllllll}12 & 1 & 2 & 3 & 4 & 12 & 5 & 6 & 7 & 8 & 9 & 10 & 12\end{array}$
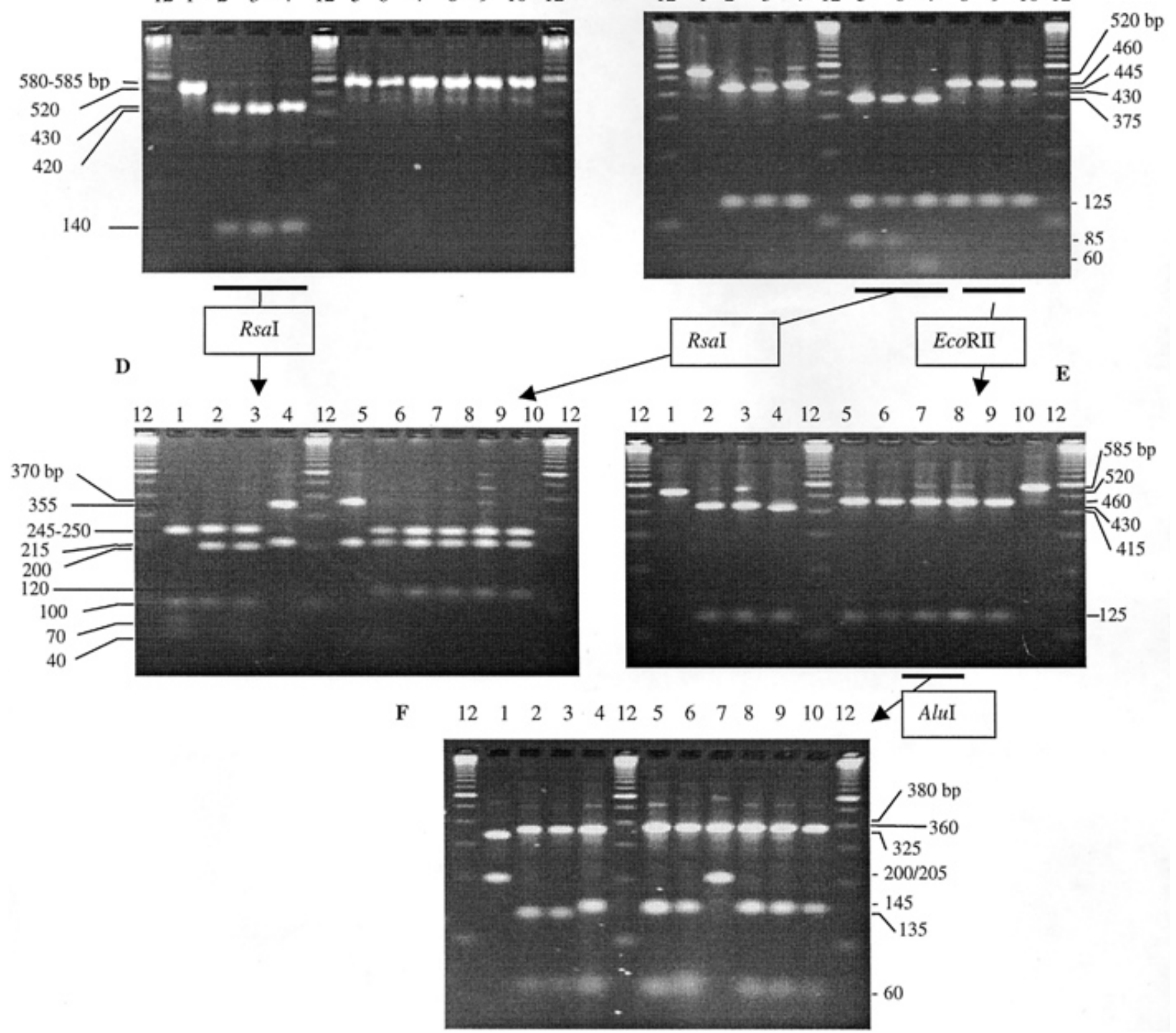

Fig. 2. Diagrammatic representation of the decision strategy for identification of isolates of the Leptosphaeria maculans species complex based on internal transcribed spacer (ITS) size polymorphism and restriction fragment length polymorphism following digestion with five restriction enzymes. A, Size polymorphism generated following polymerase chain reaction amplification of the ITS region using PN3 and PN10 as primers. Profiles generated following digestion of the amplified region with B, BamHI; C, HaeIII; D, RsaI; E, EcoRII; and F, AluI. Lane 1, Phoma nigrificans isolate Phb; 2, Tox ${ }^{+}$isolate 'Leroy' (IBCN80); 3, Tox ${ }^{+}$isolate H5; 4, 'Lepidium' isolate Lep-2 (IBCN84); 5, 'Thlaspi' isolate 92-01-2 (IBCN65); 6, 'Erysimum' isolate Ery-2 (IBCN83); 7, NA2 isolate 'Unity' (IBCN81); 8, NA1 isolate PHW1270 (IBCN93); 9, NA1 isolate Ph3; 10, NA3 isolate PHW1268 (IBCN91); 11, negative control, in which DNA is replaced by water; and 12, 100-bp ladder. Indicative size of the fragments generated following restriction of the ITS region is given (in bp). 
[17]), PN10 hybridizes to bases 33 to 54 of the 26S. As a consequence, ITS1-5.8S-ITS2 sequences were estimated as 435 to $445 \mathrm{bp}$ for $P$. nigrificans, 470 to $475 \mathrm{bp}$ for Tox ${ }^{+}$isolates, 485 to $490 \mathrm{bp}$ for the 'Lepidium' isolate, and 495 to $500 \mathrm{bp}$ for all Tox ${ }^{0}$ isolates as well as the 'Thlaspi' and 'Erysimum' isolates. These data are in accordance with published data in which the size of ITS1-5.8SITS2 was $470 \mathrm{bp}$ for one Tox $^{+}$isolate, $498 \mathrm{bp}$ for NA2 isolates, and 499 bp for one 'Thlaspi' isolate (Table 3). These data were further substantiated with ITS sequencing of other isolates of the species complex, giving an ITS size of $439 \mathrm{bp}$ for $P$. nigrificans, 481 bp for the 'Lepidium' isolate, 496 or 497 bp for NA1 isolates, $499 \mathrm{bp}$ for the NA3 isolate, and $497 \mathrm{bp}$ for the 'Erysimum' isolate (Table 3).

PCR amplification using conidia as a template. The use of conidia as a PCR template instead of DNA allowed the amplification of one single band whose size was identical to that generated when using DNA (Fig. 1). The amount of DNA generated by the PCR was sufficient to perform at least five restriction reactions (data not shown).

The feasibility of ITS-based identification following PCR with conidia was further checked on conidia developing on cotyledons inoculated with known $\mathrm{Tox}^{+}$isolates. As with DNA or conidia obtained in axenic cultures, a 555- to 560-bp band was consistently amplified following PCR using the PN3 and PN10 primers (data not shown).

RFLP and restriction maps. With the main exception of XmaI, which did not display any restriction site in all the isolates listed in Table 1, all the selected enzymes digested the ITS region in at least one of the isolates (Figs. 2 and 3).

Some of these enzymes did not generate any restriction length polymorphism in addition to what was due to the initial size polymorphism observed between isolates in the undigested ITS. This was due to the presence of highly conserved restriction sites, mainly in the 5.8S (i.e., EcoRI, Sau3AI, ClaI, NcoI, SphI [one site], StyI [two sites], and TaqI [three sites]). Additional conserved restriction sites were observed in ITS1 for all L. maculans isolates (HinfI and StyI sites) and in ITS2 for all isolates including P. nigrificans (RsaI, AluI, HinfI, and MspI). One HaeIII site was highly conserved in ITS2 of all L. maculans isolates (Fig. 3).

Ten restriction enzymes generated fragment length polymorphism that could be used to discriminate each component of the species complex. Such a discrimination could be based on (i) a variable number of sites of a particular restriction enzyme, giving rise to a variable number of fragments generated following the digestion. This was observed in the cases of HaeIII (two fragments for NA1, NA3, Tox ${ }^{+}$, and 'Lepidium' isolates; three fragments for 'Erysimum' and 'Thlaspi' isolates; and four fragments for NA2 isolates), AluI (two fragments for NA2 isolates and $P$. nigrificans and three fragments for all the other isolates), EcoRII (three fragments for the 'Lepidium' isolates and two fragments for all the other isolates except NA3 and P. nigrificans), RsaI (two fragments for 'Lepidium' and 'Thlaspi' isolates, three fragments for the remaining L. maculans isolates, and five fragments for P. nigrificans), and MspI (three fragments for the 'Erysimum' isolate and two fragments for all the other isolates) (Figs. 2 and 3). Or the discrimination could be based on (ii) the presence/absence of a single restriction site, giving rise to either one uncut fragment or two bands following digestion. This was the case for BamHI and $A c c \mathrm{I}$ sites (only present in Tox ${ }^{+}$and 'Lepidium' isolates), NlaIV site (only present in Tox ${ }^{+}$, 'Lepidium', and 'Erysimum' isolates), HindIII site (only present in NA2, 'Lepidium', and 'Thlaspi' isolates, and in $P$. nigrificans), EcoRII and ScrFI sites (absent in $P$. nigrificans and the NA3 isolate), and one HaeIII site (absent in $P$. nigrificans) (Figs. 2 and 3).

The restriction maps obtained for the NA2, Tox ${ }^{+}$, and 'Thlaspi' isolates are consistent with previously published sequence data (accessions M96384 for the Tox ${ }^{+}$isolate [17]; M96663 for the 'Thlaspi' isolate [17]; and M96383, U19274 [17], and L07735 [V. M. Morales and J. L. Taylor, unpublished data] for NA2 isolates).

Decision strategy for identification of species of the complex. Because of the small size of its ITS region, P. nigrificans could be easily discriminated from all other $L$. maculans isolates. ITS ampli-

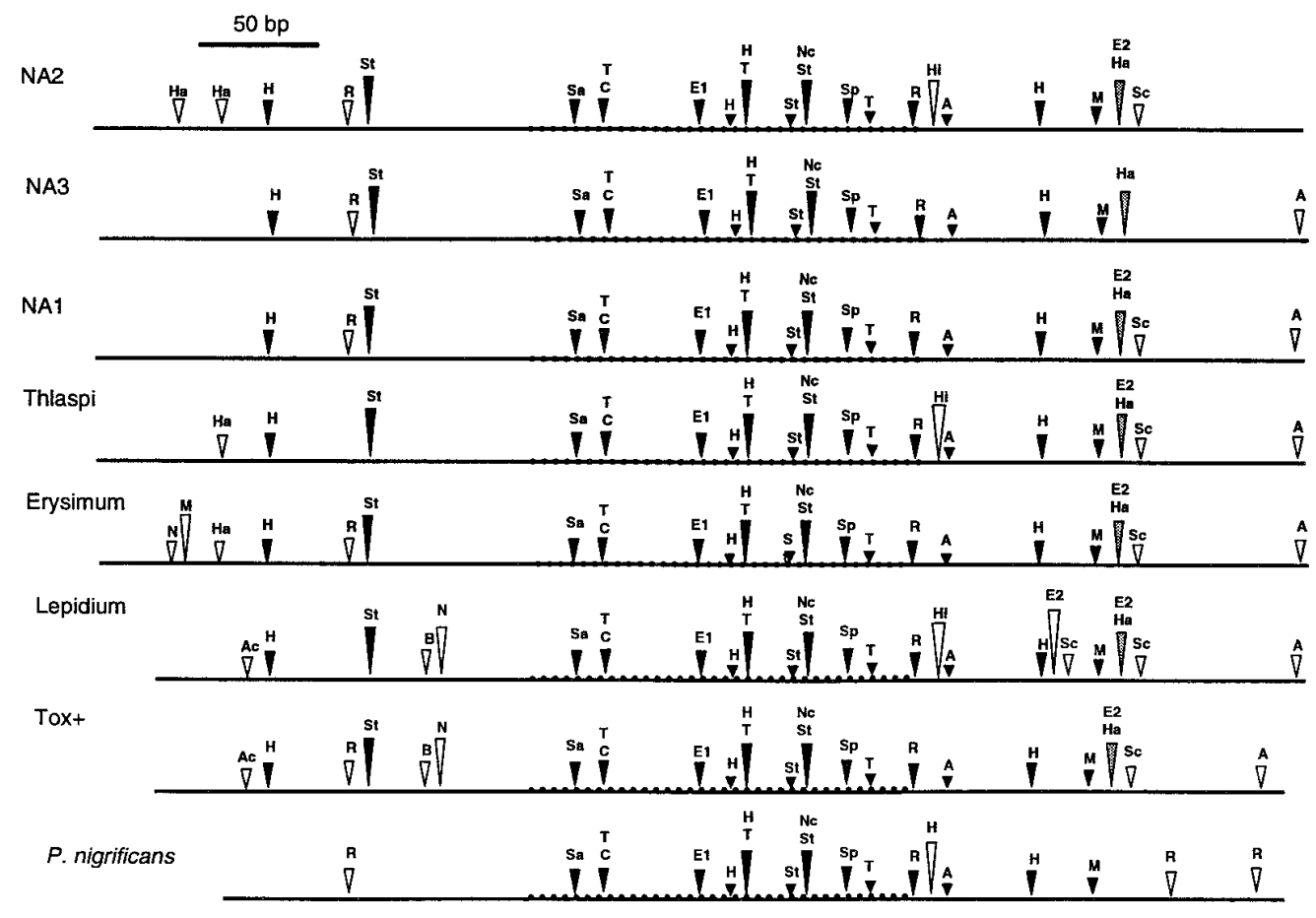

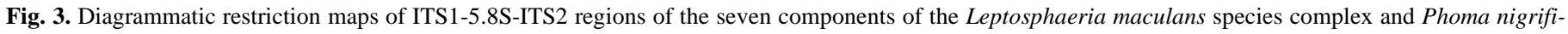

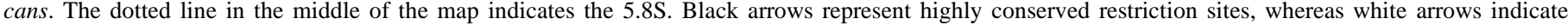

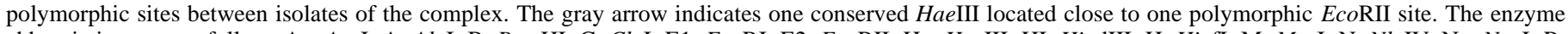

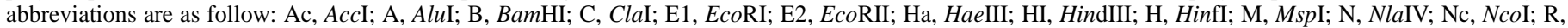
RsaI; Sa, Sau3AI; Sc, ScrFI; Sp, SphI; S, StyI; and T, TaqI. 
fication from DNA or conidia also readily discriminated Tox $^{+}$and 'Lepidium' isolates from all other isolates based on size polymorphism of the amplified region. However, an easier-to-interpret discrimination was obtained by additional restriction with $\mathrm{BamHI}$, which generated one 140-bp fragment and one 420- to 430-bp fragment only in $\mathrm{Tox}^{+}$and 'Lepidium' isolates, whereas other ITS were uncut (Fig. 2B). Apart from a 10-bp size polymorphism that may be difficult to visualize in agarose gels, discrimination between Tox $^{+}$and 'Lepidium' isolates was attained by digestion with $R s a$ I (three bands in $\mathrm{Tox}^{+}$and two in the 'Lepidium' isolate) (Fig. 2D).

No ITS size polymorphism was observed between NA1, NA2, NA3, 'Thlaspi', and 'Erysimum' isolates (Fig. 2A). Digestion with HaeIII discriminated NA1 and NA3 isolates (one restriction site) from 'Thlaspi' and 'Erysimum' (two restriction sites) and NA2 isolates (three restriction sites). However, the discrimination between 'Thlaspi'/'Erysimum' and NA2 was not easy to visualize, as it consisted of a restriction of an approximately 80-bp fragment in approximately 60- and approximately 20-bp fragments (Figs. 2C and 3). NA1 could be further discriminated from NA3 by digestion with $E c o$ RII or $S c r F I$, displaying no sites in the ITS region of the NA3 isolate (Fig. 2E). Digestion with RsaI could easily discriminate between the 'Thlaspi' (one restriction site) and 'Erysimum'/ NA2 isolates (two restriction sites) (Fig. 2D). Finally, discrimination between 'Erysimum' and NA2 isolates could be achieved by digestion with HindIII or AluI (Fig. 2F).

The accuracy of the restriction profiles obtained by digesting with three informative enzymes (RsaI, EcoRII, and $A l u \mathrm{I})$ was further assessed on 2 additional NA2, 1 additional 'Thlaspi', 11 additional $\mathrm{Tox}^{+}$, and 30 additional NA1 isolates. No site polymorphism was observed between individual isolates within each of the subgroups (data not shown). In contrast, the reproducibility of the restriction profiles could not be checked for the NA3, 'Erysimum', and 'Lepidium' isolates, as only one representative of each of these isolates was available in the IBCN collection. In addition, similar isolates were not found in the set of 44 isolates used for the validation of the decision strategy (Table 2).

Large-scale analysis of French populations of $\boldsymbol{L}$. maculans. All of the 356 French field isolates were grown in axenic conditions promoting pycnidium differentiation and were identified according to size polymorphism following PCR of the ITS region using conidia as a PCR template. All of the 356 isolates but 5 could be unambiguously ascribed to either the $\operatorname{Tox}^{+}$or the $\operatorname{Tox}^{0}$ group according to the size of the amplified fragment. Of these 351 isolates, 288 were $\operatorname{Tox}^{+}$and 63 were Tox ${ }^{0}$. The $63 \operatorname{Tox}^{0}$ were further submitted to RFLP-PCR of the ITS region with BamHI, $R s a \mathrm{I}, H a e \mathrm{III}, E c o$ RII, and AluI and could unequivocally be ascribed to the NA1 subgroup (data not shown).

\section{DISCUSSION}

The objective of our research was to propose a simple procedure for identifying all members of the L. maculans species complex, allowing large-scale analysis of the pathogen populations in all Brassica-growing regions of the world. For such a purpose, we used an international collection of L. maculans isolates collected in three continents, i.e., North America, Europe, and Australia, including reference isolates identified on the basis of RFLP and isozyme studies $(7,11)$.

In the current study, it was shown that (i) restriction site polymorphism of the ITS region is sensitive enough to discriminate between the seven subgroups of the complex gathered in the IBCN collection; (ii) site polymorphism is highly conserved within the 'Thlaspi', Tox ${ }^{+}, \mathrm{NA} 1$, and NA2 subgroups; (iii) consistent amplification and restriction of the ITS region can be achieved using conidia as a PCR template; and (iv) the simplified identification protocol proposed here is useable for large-scale identification of field isolates.
Following ITS amplification with universal primers, three main groups of isolates can be discriminated among the eight reference isolates analyzed: (i) P. nigrificans; (ii) Tox ${ }^{+}$and 'Lepidium' isolates; and (iii) NA1, NA2, NA3, 'Thlaspi', and 'Erysimum' isolates. For identification purposes, ITS size polymorphism can allow a discrimination between these three groups of isolates. However ITS size polymorphism is insufficient for a discrimination of isolates within each group. This was the case for NA1, NA2, NA3, 'Thlaspi', and 'Erysimum' isolates, in which no size polymorphism was evident between ITS regions, and also in the $\mathrm{Tox}^{+} /$'Lepidium' group, in which a 10-bp difference in size is likely to be unseen on agarose gels. Twelve restriction enzymes out of the nineteen used in this study have recognition sequences in the ITS1 and ITS2 regions, among which six restriction enzymes defined seven highly conserved sites among $L$. maculans isolates. P. nigrificans remains apart from the isolates of the L. maculans complex, as it has only four of these conserved sites, all of them being located in ITS2, which has been reported as being less variable than ITS1 (16). P. nigrificans differed from other isolates of the complex by 7 to 14 restriction site polymorphisms, depending on the reference isolate considered. In contrast, only two to five polymorphisms discriminated between the NA1, NA2, NA3, 'Thlaspi', and 'Erysimum' isolates. Finally, only one site polymorphism was observed between the ITS1 of the 'Lepidium' isolate and that of the Tox ${ }^{+}$isolates, as compared with four to six polymorphisms when compared with the other members of the complex. The current study shows that, in conjunction with size polymorphism, four or five restriction endonucleases are sufficient to discriminate the seven components of the complex. If considering that NA1, NA2, and $\mathrm{Tox}^{+}$are the main components of the complex and only these need to be routinely identified, only two restriction endonucleases, i.e., BamHI and either AluI or HaeIII, are enough for such a discrimination.

The consistency of restriction profiles was checked on DNA from 49 additional isolates from Canada, France, Denmark, the United Kingdom, and Poland. It has to be emphasized that no other NA3-, 'Erysimum'-, and 'Lepidium'-type isolate was present among these additional isolates and that only one isolate of each is available in the IBCN collection. In addition, no ITS sequence data has been published for these isolates. It still has to be demonstrated that the NA3 subgroup is representative of a clearly defined genetic entity, as only one NA3 isolate has ever been described in the literature (11). 'Erysimum'- and 'Lepidium'-type isolates have never been isolated from cultivated Brassica species (19, this study) and probably represent species with a narrow host range. In contrast, one additional 'Thlaspi' isolate was present in the IBCN collection, and its ITS was compared, with no inconsistency, with that of isolate IBCN64 and with the ITS sequences previously published for two other 'Thlaspi'-type isolates (17). 'Thlaspi'-type isolates seem to be frequent in Canada, where they infect $B$. napus in addition to T. arvense (19). However, no 'Thlaspi'-type isolate was found in the current study when analyzing isolates obtained from B. napus in Europe. In addition, the only isolate obtained from $T$. arvense in Poland was clearly distinct from 'Thlaspi'-type isolates from Canada. In contrast to L. maculans from cruciferous weeds and the NA3 isolate, NA2 isolates have been studied in detail, as ITS sequences from four different isolates are currently available (accession numbers M96663, L07735, U19274, and M96383). Restriction profiles obtained in the current study for the NA2 isolates 'Unity' (IBCN81), IBCN82, and IBCN63 are consistent with these sequence data. Unfortunately, all of these are Canadian isolates, whereas NA2 isolates also occur in Australia and South Africa (11). ITS studies of NA2 isolates obtained from these countries should now be necessary to further assess whether any polymorphism occurs within the NA2 subgroup. ITS restriction profiles were identical for all the NA1 isolates from Poland, France, and the United Kingdom and were consistent with sequence data from the PHW1270 reference isolate (this study). Finally, no 
restriction site polymorphism was observed between the ITS of 13 Tox $^{+}$isolates from Canada, France, Denmark, Poland, and the United Kingdom, which is in accordance with the very low polymorphism observed between ITS sequence data of five Canadian and Australian Tox ${ }^{+}$isolates (17). In conclusion, with the main exception of the NA3, 'Erysimum', and 'Lepidium' isolates that need additional validation, the data presented here indicate that site polymorphism is conserved within each group, therefore suggesting that each population may be distinct and is amenable to simple discrimination based on restriction fragment analysis.

Even when easy to perform, one main problem remains to be solved to make ITS-based PCR sufficiently user-friendly for largescale identification of components of the complex. DNA extraction procedures that rely either on toxic solvents or costly kits have to be avoided so that the analysis can be performed in most small-scale analytical laboratories. Although a few methods simplifying the DNA extraction step have been reported for fungal pathogens, these usually involve mechanical disruption of mycelium, use of organic solvents, and various centrifugation steps. Only in a few cases was PCR directly performed on spores following either a freeze-and-thaw protocol (28) or microwave irradiation (6). In one case, however, it has been reported that PCR can be performed using intact conidiospores as target DNA, following a prolonged initial denaturation step at $94^{\circ} \mathrm{C}$ (3). However, no such simplified protocol was currently available for the L. maculans species complex. In this paper, we report direct amplification from conidia occurring either on symptomatic leaf tissue or in axenic culture, following a 4-min denaturation step at $95^{\circ} \mathrm{C}$ preceding the PCR. In contrast to many other fungi, conidia of L. maculans are particularly amenable to direct PCR, as they are small thin-walled spores, devoid of melanin, and contain a small amount of cytoplasm. In this species, chromosomal DNA for pulsed-field gel electrophoresis is obtained from conidia without the need of the protoplasting step (12,21). As a consequence, disruption of the conidial wall and availability of DNA for PCR can be easily obtained without microwave treatment, freeze-and-thaw, or prolonged denaturation in the PCR, particularly when the amplification target is highly repeated in the genome, as it is the case for rDNA. The efficacy of the amplification from conidia was further assessed on sporulating cultures of 356 French field isolates, as the frequency of successful ITS amplification from conidia exceeded $98 \%$. Following ITS restriction analyses with five enzymes, only Tox $^{+}$and $\operatorname{Tox}^{0}$ NA1 were identified in the sampling, therefore suggesting, in accordance with previous studies, that only these two subgroups can be isolated from B. napus in France (7). In practice, large-scale analyses of French field isolates are now routinely performed using PCR from conidia followed by two further digestions of the PCR product with BamHI and EcoRII.

The simplified protocol proposed here allows direct PCR identification from sporulating leaf lesions. However, as most species of the complex can develop systemic growth within the plants without expressing symptoms and sporulation, a cultivation of the isolates is still necessary for a precise identification of species of the complex isolated from stem cankers or symptomless plants. On the basis of ITS sequence data, our objective will now be to design primers specific for each component of the species complex. This will allow us to avoid the restriction steps and to propose a twostep or multiplex PCR for routine identification of the L. maculans species complex, which will have to be further adapted for an in planta analysis.

\section{ACKNOWLEDGMENTS}

This research was supported by the FAIR CT96-1669 contract from the EU (coordinator M. H. Balesdent). M. Jedryczka was funded by a research-training grant from INRA, Direction des Relations Internationales. We thank G. Séguin-Swartz (Agriculture and Agri-Food, Saskatoon, Can- ada) and all the partners who contributed to the International Blackleg of Crucifers Network (IBCN) collection: H. H. Hoppe (University of Göttingen, Germany), B. J. Howlett (University of Melbourne, Australia), Z. Karolewski (Agricultural University, Poznan, Poland), J. Wöstemeyer (Fiedrich-Schiller Universität, Jena, Germany), H. Brun (INRA, Le Rheu, France), A. Mengistu and P. H. Williams (University of Wisconsin, Madison), and P. H. Goodwin (University of Guelph, Canada). Activities of the IBCN come under the auspices of the ISPP (International Society for Plant Pathology). We also thank the field and lab technicians from the CETIOM who isolated the French field isolates used in this study.

\section{LITERATURE CITED}

1. Ansan-Melayah, D., Balesdent, M. H., Buée, M., and Rouxel, T. 1995. Genetic characterization of AvrLm1, the first avirulence gene of Leptosphaeria maculans. Phytopathology 85:1525-1529.

2. Ansan-Melayah, D., Rouxel, T., Bertrandy, J., Letarnec, B., MendesPereira, E., and Balesdent, M. H. 1997. Field efficiency of Brassica napus specific resistance correlates with Leptosphaeria maculans population structure. Eur. J. Plant Pathol. 103:835-841.

3. Aufauvre-Brown, A., Tang, C. M., and Holden, D. W. 1993. Detection of gene-disruption events in Aspergillus transformants by polymerase chain reaction direct from conidiospores. Curr. Genet. 24:177-178.

4. Balesdent, M. H., Gall, C., Robin, P., and Rouxel, T. 1992. Intra-specific variation in soluble mycelial protein and esterase patterns of Leptosphaeria maculans French isolates. Mycol. Res. 96:677-684.

5. Dellaporta, S. L., Wood, J., and Hicks, J. B. 1983. A plant DNA minipreparation: Version II. Plant Mol. Biol. Rep. 1:19-21.

6. Ferreira, A. V. B., and Glass, N. L. 1996. PCR from fungal spore after microwave treatment. Fungal Genetics Newsletter 43. University of Kansas Medical Center, Kansas City.

7. Gall, C., Balesdent, M. H., Desthieux, I., Robin, P., and Rouxel, T. 1995. Polymorphism of Tox ${ }^{0}$ Leptosphaeria maculans isolates as revealed by soluble protein and isozyme electrophoresis. Mycol. Res. 99:221-229.

8. Goodwin, P. H., and Annis, S. L. 1991. Rapid identification of genetic variation and pathotype of Leptosphaeria maculans by random amplified polymorphic DNA assay. Appl. Environ. Microbiol. 57:2482-2486.

9. Jedryczka, M., Fitt, B. D. L., Kachlicki, P., Lewartowska, E., Balesdent, M. H., and Rouxel, T. A comparison between Polish and UK isolates of Leptosphaeria maculans, cause of stem canker of winter oilseed rape. IOCB Bull. In press.

10. Jedryczka, M., Lewartowska, E., and Frencel, I. 1995. Is Phoma nigrificans the potential pathogen of oilseed rape? Pages 625-627 in: Proc. Int. Rapeseed Congr., 9th. GCRIC (Groupe Consultatif International de Recherche sur le Colza), Paris.

11. Koch, E., Song, K., Osborn, T. C., and Williams, P. H. 1991. Relationship between pathogenicity and phylogeny based on restriction fragment length polymorphism in Leptosphaeria maculans. Mol. Plant-Microbe Interact. 4:341-349.

12. Leclair, S., Ansan-Melayah, D., Rouxel, T., and Balesdent, M. H. 1996. Meiotic behaviour of the minichromosome in the phytopathogenic ascomycete Leptosphaeria maculans. Curr. Genet. 30:541-548.

13. Louanchi, M. 1993. Contribution à l'étude de Rigidoporus lignosus, agent du pourridié blanc des racines d'Hevea brasiliensis: Étude de la diversité génétique des populations et détection par les méthodes immunoenzymatiques. Ph.D. thesis. University Paris-Sud-Orsay, France.

14. Marcinkowska, J., and De Gruyter, J. 1996. Phoma nigrificans (P. Karst.) Boerema et al., a new species for Poland. J. Phytopathol. 144:53-54.

15. Meyer, W., Lieckfeldt, E., Wöstemeyer, J., and Börner, T. 1992. DNA fingerprinting for differentiating aggressivity groups of the rape seed pathogen Leptosphaeria maculans. Mycol. Res. 96:651-657.

16. Morales, V. M., Jasalavich, C. A., Pelcher, L. E., Petrie, G. A., and Taylor, J. L. 1995. Phylogenetic relationship among several Leptosphaeria species based on their ribosomal DNA sequences. Mycol. Res. 99:593-603.

17. Morales, V. M., Pelcher, L. E., and Taylor, J. L. 1993. Comparison of the $5.8 \mathrm{~s}$ rDNA and internal transcribed spacer sequences of isolates of Leptosphaeria maculans from different pathogenicity groups. Curr. Genet. 23:490-495.

18. Pedras, M. S. C. 1995. Phytoalexin detoxification and phytotoxin biosynthesis in blackleg fungi. Blackleg News 5:2-4.

19. Petrie, G. A. 1969. Variability in Leptosphaeria maculans (Desm.) Ces. \& De Not., the cause of blackleg of rape. Ph.D. thesis. University of Saskatoon, Saskatoon, Canada.

20. Plummer, K. M., Dunse, K., and Howlett, B. J. 1994. Non-aggressive strains of the blackleg fungus, Leptosphaeria maculans, are present in Australia and can be distinguished from aggressive strains by molecular analysis. Aust. J. Bot. 42:1-8.

21. Plummer, K. M., and Howlett, B. J. 1993. Major chromosome length 
polymorphisms are evident after meiosis in the phytopathogenic fungus Leptosphaeria maculans. Curr. Genet. 24:107-113.

22. Rouxel, T., Balesdent, M. H., Séguin-Swartz, G., and Gugel, R. 1995. How many pathogens cause blackleg of crucifers? Blackleg News 4:1-7.

23. Rouxel, T., Gall, C., and Balesdent, M. H. 1994. Du polymorphisme au complexe d'espèces: Combien d'agents pathogènes sont impliqués dans la nécrose du collet du colza? Agronomie 14:413-432.

24. Rouxel, T., and Séguin-Swartz, G. 1995. International blackleg of crucifers network. Blackleg News 5:15-16.

25. Schäfer, C., and Wöstemeyer, J. 1992. Random primer dependent PCR differentiate aggressive from non-aggressive isolates of the oilseed rape pathogen Phoma lingam (Leptosphaeria maculans). J. Phytopathol. 136: 124-136
26. Séguin-Swartz, G. 1994. International blackleg network. Blackleg News 4:7.

27. White, T. J., Bruns, T., Lee, S., and Taylor, J. 1990. Amplification and direct sequencing of fungal ribosomal RNA genes for phylogenetics. Pages 315-322 in: PCR Protocols. A Guide to Methods and Applications. M. A. Innis, D. H. Gelfand, J. J. Sninsky, and T. J. White, eds. Academic Press, Inc., San Diego, CA.

28. Xu, J. R., and Hamer, J. E. 1995. Assessment of Magnaporthe grisea mating type by spore PCR. Fungal Genetics Newsletter 42. University of Kansas Medical Center, Kansas City.

29. Xue, B., Goodwin, P. H., and Annis, S. L. 1992. Pathotype identification of Leptosphaeria maculans with PCR and oligonucleotide primers from ribosomal internal transcribed spacer sequences. Physiol. Mol. Plant Pathol. 41:179-188. 